\title{
EFEITO DE DIFERENTES HERBICIDAS NAS CULTURAS DE ALHO E CEBOLA
}

\author{
ROBERT DEUBER, Seç̃o de Fisiologia, JOÄO BAPTISTA FORNASIER (2) e ROGERIO \\ SALLES LISBÃO (2), Seção de Hortalịas Diversas, Instituto Agronômico.
}

\section{RESUMO}

Foram instalados dois experimentos de campo, um com alho 'Lavínia' e outro com cebola 'Monte Alegre' e 'Roxa do 'Traviú', para estudar a eficiência de controle e a seletivididade de herbicidas. Na cultura do alho, havia os seguintes tratamentos: pendimethalin a $1,50 \mathrm{~kg} / \mathrm{ha}$, linuron a $1,00 \mathrm{~kg} / \mathrm{ha}$ e oxadiazon a $1,00 \mathrm{~kg} / \mathrm{ha}$, aplicados no dia do plantio; ioxinil a 0,50 e $0,75 \mathrm{~kg} / \mathrm{ha}$, ioxinil + oxadiazon a $0,75+0,25 \mathrm{~kg} / \mathrm{ha}$ e $0,50+0,50 \mathrm{~kg} / \mathrm{ha}$, aplicados em pós-emergência, testemunhas com e sem cultivo e com palha seca. Ocorreu uma população mista de mato com predominio de beldroega. Em contagens realizadas aos 48 e 84 dias, verificou-se excelente controle de dicotiledôneas por todos os tratamentos. Ioxinil só ou em mistura com oxadiazon, em pós-emergência, não controlou gramíneas. Nenhum tratamento herbicida reduziu o número de plantas de alho, ocorrendo os menores valores com as testemunhas com mato e com palha. As produçóes, em peso, de bulbos ocorreram na seguinte ordem decrescente: testemunha capinada $>$ oxadiazon $>$ ioxinil + oxadiazon a $0,50+0,50=$ pendimethalin $=$ testemunha com palha $=$ ioxinil + oxadiazon a $0,75+0,25 \mathrm{~kg}>$ linuron $>$ ioxinil a $0,75 \mathrm{~kg}$ $>$ ioxinil a $0,50 \mathrm{~kg}>$ testemunha com mato. Na cultura da cebola, havia os seguintes tratamentos: pendimethalin a $1,50 \mathrm{~kg} / \mathrm{ha}$, linuron a $1,00 \mathrm{~kg}$, oxadiazon a $1,00 \mathrm{~kg}$ 'e chloroxuron a $4,00 \mathrm{~kg}$, aplicados no dia do transplantio; ioxinil a $0,50 \mathrm{~kg}$ e $0,75 \mathrm{~kg}$, oxadiazon + ioxinil a $0,75+0,25 \mathrm{~kg}$, idem a $1,00+0,25 \mathrm{~kg}$ e a $1,00+$ $1,00 \mathrm{~kg}$, e linuron a $1,00 \mathrm{~kg}$, todos aplicados 32 dias após o transplantio, testemunhas com e sem capina. Ocorreu uma população predominante de dicotiledôneas com maior frequiência de beldroega e de quenopódio. A avaliação, realizada aos 48 dias, mostrou excelente controle de dicotiledôneas por todos os tratamentos, com valores acima de $95 \%$. O ioxinil, só ou em mistura com oxadiazon, não controlou gramíneas, e o chloroxuron apresentou o menor controle geral, mas ainda satisfatório. O oxadiazon em PRE e o linuron em Pós foram os mais eficientes no controle de gramineas. Não houve diferenças entre as produções de cebola nos diferentes tratamentos.

(1) Trabalho parcialmente apresentado no XIII Congresso Brasileiro de Herbicidas e Ervas Daninhas, Itabuna, Ilhéus (BA), 1980. Recebiđo para publicação a 16 de setembro de 1981.

(2) Com bolsa de suplementação do CNPq. 


\section{INTRODUÇÃO}

Alho e cebola são culturas afins, sendo, a primeira, uma olericola que vem adquirindo importância nos últimos anos, pela grande evasão de divisas com sua importação, uma vez que a produção nacional, embora em expansão, ainda não supre as necessidades do País. A cebola, por sua vez, é uma hortaliça que apresenta, atualmente, uma tendência crescente de produção, devido não só à expansão da área como, também, a aumentos na produtividade.

Segundo dados estatísticos da CEAGESP (Companhia de Entrepostos e Armazens Gerais de São Paulo), foram comercializadas, em $1980,181.428$ caixas de $10 \mathrm{~kg}$ de alho estrangeiro, no valor de 212.127.431 cruzeiros, e 21.032 caixas de $10 \mathrm{~kg}$ de alho nacional, no valor de 26.675 cruzeiros. No mesmo ano, foram comercializadas 2.223 .219 sacas de $20 \mathrm{~kg}$ de cebola no valor de 930.995.188 cruzeiros.

As plantas daninhas constituem sério problema para tais culturas, pois ambas as olerícolas, em razão de possuirem folhas eretas e finas, cobrem imperfeitamente o solo, permitindo a germinação e desenvolvimento de ervas daninhas em qualquer fase da cultura $(5,6)$. Além da concorrência em luz, água e nutrientes, as plantas daninhas causam aumento do custo de mão-de-obra, reduzem a produção, afetam a qualidade dos bulbos (1) e hospedam pragas que podem atacar diretamente a cultura ou funcionar como vetores de doenças.

Todos esses problemas fazem com que o êxito das culturas de alho e cebola dependa do uso correto de herbicidas, uma vez que a mão-de-obra disponivel, na época adequada, está cada vez mais difícil e cara $(3,4)$.

Todavia, essa prođução é uma atividade muito especializada, com áreas em cultivos das mais diversas condições de clima e solo, sendo o resultado da aplicação de herbicidas nem sempre satisfatório, se não forem tomadas precauções na escolha do produto a ser utilizado e na dose a ser aplicada. Dessa forma, faz-se necessário o estudo da eficiência de novos herbicidas no controle de ervas daninhas e sua seletividade, melhorando, assim, a tecnologia da produção dessas hortaliças importantes para o consumo.

\section{MATERIAL E MÉTODOS}

Os experimentos foram instalados, em áreas contíguas, em um latossolo roxo, série Barão (7), de textura barrenta, no Centro Experimental de Campinas, com as seguintes características físicas e químicas nos $20 \mathrm{~cm}$ superiores: $36,2 \%$ de argila, $5,0 \%$ de limo, $25,6 \%$ de areia fina, $33,2 \%$ de areia grossa; $\mathrm{pH} 5,65,3,27 \%$ de matéria orgânica e, os teores, em e.mg. $/ 100 \mathrm{~g}$ de TFSA, 0,6 de $\mathrm{PO}_{4}^{-3}$, 0,3 de $\mathrm{K}^{+}$e 3,45 de $\mathrm{Ca}^{+2}+\mathrm{Mg}^{+2}$.

\subsection{Alho (Allium sativum L.)}

A 17 de maio de 1977, foi realizado o plantio de bulbilhos do 
cultivar Lavínia em parcelas de $1,0 \times 1,5 \mathrm{~m}$, utilizando-se quarenta bulbilhos espaçados de $0,10 \mathrm{~m} \times$ $0,20 \mathrm{~m}$ e a seguinte adubação básica por metro quadrado: $5 \mathrm{~kg}$ de composto, $150 \mathrm{~g}$ de superfosfato simples, $20 \mathrm{~g}$ de cloreto de potássio e $2 \mathrm{~g}$ de bórax comercial. Em cobertura, foram aplicados $15 \mathrm{~g} / \mathrm{m}^{2}$ de sulfato de amônio aos 30 e 45 dias após a emergência dos bulbilhos. O delineamento usado foi blocos ao acaso, com quatro repetições dos seguintes tratamentos: a) pendimethalin $\left({ }^{3}\right)=\mathrm{N}$ (1 - etil - propil) - 3,4 - dimetil - 2,6 dinitrobenzanamina, a $1,50 \mathrm{~kg} / \mathrm{ha}$; b) linuron $\left({ }^{4}\right)=3-(3,4$ - diclorofenil) - 1 - metoxi - 1 - metil - uréia, a $1,00 \mathrm{~kg} / \mathrm{ha} ;$ c) oxadiazon $\left({ }^{5}\right)=$ 2 - tertiobutil - 4 - (2,4 - dicloro - 5 - isopropil - oxifenil ) - 1,3,4 - oxadiazolina -5 - one, a $1,00 \mathrm{~kg} / \mathrm{ha}$, todos aplicados em pré-emergência, um dia após o plantio; d) ioxinil $\left({ }^{6}\right)$ $=$ 4-hidroxi-3,5-di-iodobenzonitrilo, na forma de éster, a $0,50 \mathrm{~kg} /$ ha; e) ioxinil, a $0,85 \mathrm{~kg} / \mathrm{ha}$; f) ioxinil a $0,75 \mathrm{~kg} / \mathrm{ha}+$ oxadiazon a $0,25 \mathrm{~kg} / \mathrm{ha} ; \mathrm{g})$ ioxinil a $0,50 \mathrm{~kg} / \mathrm{ha}$ + oxadiazon a $0,50 \mathrm{~kg} / \mathrm{ha}$, todos aplicados 35 dias após o plantio; h) sem herbicida e i) sem herbicida e com cobertura morta (palha de arroz). Na aplicação de pósemergência, as plantas de alho estavam com $0,25 \mathrm{~m}$ de altura média e com quatro a cinco folhas. As plantas daninhas tinham altura média de $0,20 \mathrm{~m}$, ocorrendo principalmente as seguintes espécies: beldroega (Portulaca oleracea L.), caruru (Amaranthus spp.), mar-

\footnotetext{
(3) Herbadox 500 .

(4) Afalon $50 \mathrm{WP}$

(5) Ronstar $250 \mathrm{EC}$.

(6) Totril $250 \mathrm{EC}$
}

cela (Gnaphalium spicatum Lam.), capim-gordura (Melinis minutiflora Beauv.), capim-pé-de-galinha (Eleusine indica Gaertn.) e capim-de-colchão (Digitaria horizontalis Willd.).

As parcelas em que se aplicou herbicida não receberam cobertura morta.

A primeira contagem de ervas daninhas em todos os tratamentos foi realizada aos 48 dias após a aplicação de PRÉ e aos 14 dias após a aplicação de Pós. Uma segunda contagem foi realizada decorridos 36 dias da primeira. Em ambos, contaram-se as espécies de ervas daninhas em duas amostras retangulares de $0,2 \mathrm{~m}^{2}$ por parcela.

A colheita do alho se fez com um ciclo de 126 dias, obtendo-se o número e o peso de bulbos por parcela.

\subsection{Cebola (Allium cepa L.)}

Esse ensaio foi instalado a 19 de maio de 1977, com o transplantio de mudas dos cultivares Monte Alegre e Roxa do Traviú. As parcelas mediam $2,40 \times 2,55 \mathrm{~m}$, com espaçamento entre linhas de $0,40 \mathrm{~m}$ e, entre mudas, de $0,15 \mathrm{~m}$. Foram plantadas três linhas de cada cultivar por parcela.

Os tratamentos aplicados foram: a) pendimethalin, a $1,5 \mathrm{~kg} /$ ha; b) linuron a $1,0 \mathrm{~kg} / \mathrm{ha}$; c) oxadiazon a $1,0 \mathrm{~kg} / \mathrm{ha}$ e d) chloroxuron $\left(^{7}\right)=\mathrm{N}-4$ (-clorofenoxi)-fenil-N'-N'-dimetiluréia, a $4,0 \mathrm{~kg} / \mathrm{ha}$, todos aplicados no mesmo dia do

(7) Tenoran 50 
transplante; e) ioxinil a $0,5 \mathrm{~kg} /$ ha; f) ioxinil a $0,75 \mathrm{~kg} / \mathrm{ha}$; g) oxadiazon a $0,75 \mathrm{~kg} / \mathrm{ha}+$ ioxinil a $0,25 \mathrm{~kg} / \mathrm{ha} ; \mathbf{h})$ idem, a $1,0+$ $0,25 \mathrm{~kg} / \mathrm{ha}$; i) idem a $1,0+1,0 \mathrm{~kg} /$ ha; j) linuron a $1,0 \mathrm{~kg} / \mathrm{ha}$, todos aplicados aos 32 dias após o transplantio; 1) testemunha sem capinar e m) testemunha sempre capinada. Por ocasião da aplicação de PóS, as plantas de cebola se apresentavam com quatro a cinco folhas e as plantas de ervas daninhas, com altura média de $0,10 \mathrm{~m}$.

As espécies de plantas daninhas presentes no local do experimento eram: beldroega, quenopódio, vassourinha e capim-de-colchão.

Aos 48 dias após o transplantio, fez-se uma contagem de ervas daninhas, com cinco amostradores circulares de $0,1 \mathrm{~m}^{2}$ por parcela. O tratamento com ervas daninhas foi capinado aos 72 dias.

A colheita do cultivar Monte Alegre foi realizada a 17 de agosto e a do Roxa do Traviú, a 22 de setembro. Os bulbos foram classificados em três tipos: de primeira, com diâmetro acima de $55 \mathrm{~mm}$; de segunda, com diâmetro entre 40 e $55 \mathrm{~mm}$ e, de terceira e conserva, com diâmetro inferior a $40 \mathrm{~mm}$.

\section{RESULTADOS E DISCUSSÃO}

\subsection{Alho}

Os resultados de controle de plantas daninhas pelos herbicidas, na primeira e segunda contagens, estão nos quadros 1 e 2 respectivamente. No quadro 2 estão, tam- bém, o número de plantas e o peso de alho produzido.

Durante um período de dez dias após a aplicação dos herbicidas de pós-emergência, as plantas de alho tratadas com ioxinil apresentavam leves manchas cloróticas, que foram desaparecendo gradativamente, não se notando qualquer alteração no crescimento.

Os herbicidas aplicados em pré-emergência realizaram um controle geral de ervas daninhas considerado excelente. O linuron apresentou, aos 48 dias, controle de gramíneas de $85,7 \%$, que foi reduzido para $66,7 \%$, aos 84 dias, o que mostra a perda de ação residual contra monocotiledôneas. $\mathrm{O}$ oxadiazon, em PRE, com controle quase total aos 84 dias, foi mais eficiente do que as misturas com ioxinil em PóS. Este, aplicado isoladamente, mostrou grande eficiência no controle de dicotiledôneas, o que concorda com as informações sobre o produto (8). O controle geral, no entanto, foi insuficiente pelo ioxinil e suas misturas com oxadiazon.

O tratamento com cobertura morta, prática rotineira na cultura do alho, garantiu um controle muito bom até aos 48 dias e perfeito para as gramíneas. Aos 48 dias, entretanta, já se verificava grande infestação de dicotiledôneas, principalmente de beldroega e caruru. Continuava o controle das gramíneas, devido ao abaixamento da temperatura do solo, sob a cobertura, tornando ainda mais adversas as condições de germinação de monocotiledôneas, já desfavoráveis no inverno. 


\begin{tabular}{|c|c|c|c|c|c|}
\hline 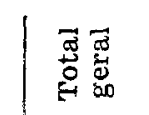 & 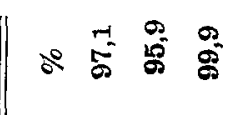 & 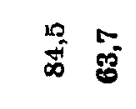 & $\vec{\sigma}$ & 离 & \\
\hline 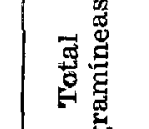 & ஃீ & $\because:$ & $\stackrel{0}{*}$ & 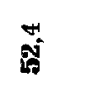 & \\
\hline 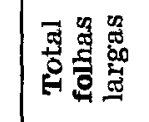 & ஃळ & 楞票 & 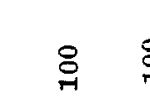 & 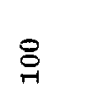 & \\
\hline & ஃ。 & : & 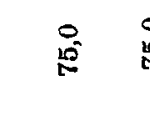 & $\stackrel{\circ}{\circ}$ & \\
\hline 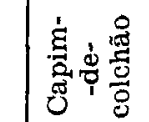 & ¿̊口 & $::$ & $:$ & 通 & \\
\hline 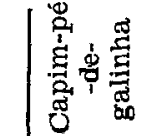 & 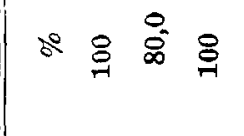 & $\therefore:$ & 品 & 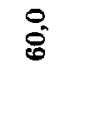 & \\
\hline 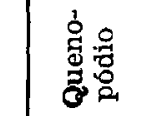 & 임 & 욤 & \& & 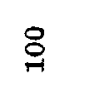 & \\
\hline 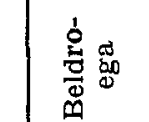 & $\because \%$ & ஓ & \& & 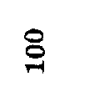 & \\
\hline ฮु & 임욤요 & \& & $\stackrel{\rho}{\circ}$ & s & \\
\hline 害器 & 总总 & : & & 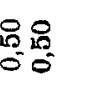 & \\
\hline & 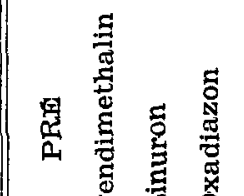 & & & & \\
\hline
\end{tabular}




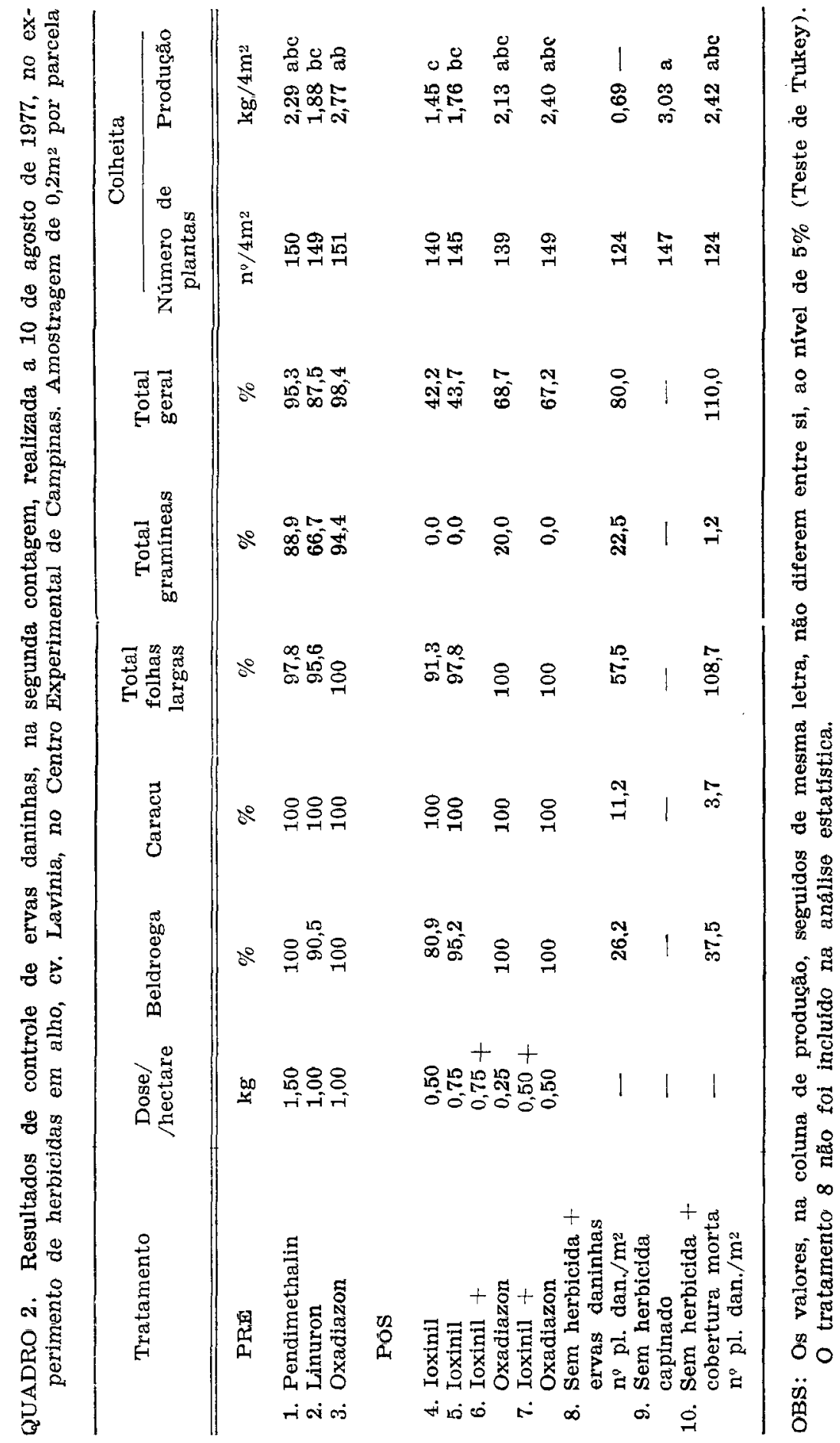


A produção de alho, avaliada pelo número de bulbos $\mathrm{e}$ seu peso por parcela, não foi afetada significativamente, quanto ao primeiro parâmetro. A análise estatística revelou que apenas o pendimethalin e o oxadiazon, em PRÉ, e as misturas de oxadiazon e ioxinil, em PóS, não diferiram da testemunha capinada. O tratamento com cobertura também não diferiu, mas é evidente que houve também redução de produção. O motivo parece ser a competição pelas plantas daninhas não controladas, ou pelos herbicidas ou pela cobertura morta.

Quanto à possível fitoxicidade causada pelos herbicidas, o linuron parece ter reduzido a produção que, no caso, nāo pode, com segurança, ser atribuída à competição pelo mato não controlado. O pendimethalin, com excelente controle, também apresentou certa redução, apesar de não significativa. Os tratamentos com ioxinil apresentaram as maiores reduções, o que deve ser atribuído ao não-controle de gramíneas, já que, em quantidade iguais de ingrediente ativo nas misturas com oxadiazon, não reduziu significativamente a produção.

A diferença de produção entre os tratamentos com e sem cobertura pode ser atribuída às plantas que nasceram a partir da metade do ciclo, causando redução pela concorrência pelos nutrientes. O tratamento capinado sempre recebeu água em abundância, e com revolvimento da superfície apresentou excelentes condições para o desenvolvimento do alho, que revelou boa produção. O tra- tamento com ervas daninhas, que não foi considerado na análise estatística, apresentou redução de $77 \%$, para um periodo de competição de 72 dias.

Os resultados obtidos indicam a necessidade de realizar estudos de competição de plantas daninhas com o alho e de tolerância dessa cultura aos herbicidas, em condições de ausência de mato, para diferentes cultivares.

\subsection{Cebola}

Os resultados de controle de plantas daninhas, pelos herbicidas, aos 48 dias após o transplantio, estão no Quadro 3 e os de produção de cebola, no Quadro 4.

Das espécies presentes, o quenopódio, por seu porte, e a beldroega, pela área ocupada, eram as mais competitivas e ocorreram em número bem elevado. No entanto, todos os herbicidas controlaram essas espécies sempre em níveis acima de $93 \%$. O controle de gramíneas foi excelente pelo pendimethalin e muito bom pelo oxadiazon em PRÉ e total pelo linuron em Pós. Este herbicida não controlou nenhuma gramínea em PRE, o que não ocorreu no experimento com alho.

Os resultados de controle pelo linuron concordam com os de trabalho anteriormente realizado, mas não os de chloroxuron, que foram excelentes naquele, com as mesmas espécies de ervas daninhas (2).

Não foram verificados quaisquer sintomas de fitotoxidade na cebola, em qualquer dos tratamentos herbicidas. 


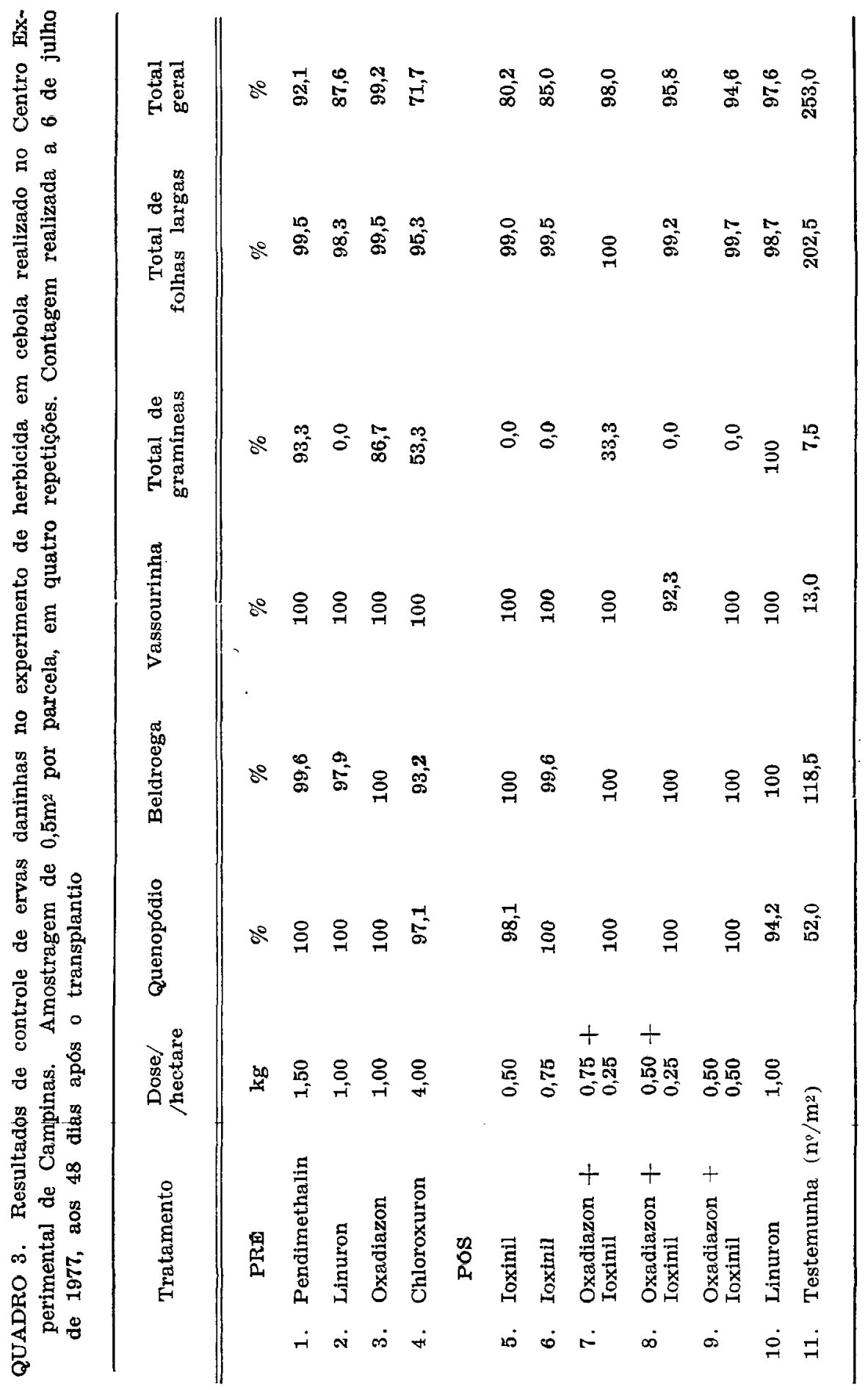




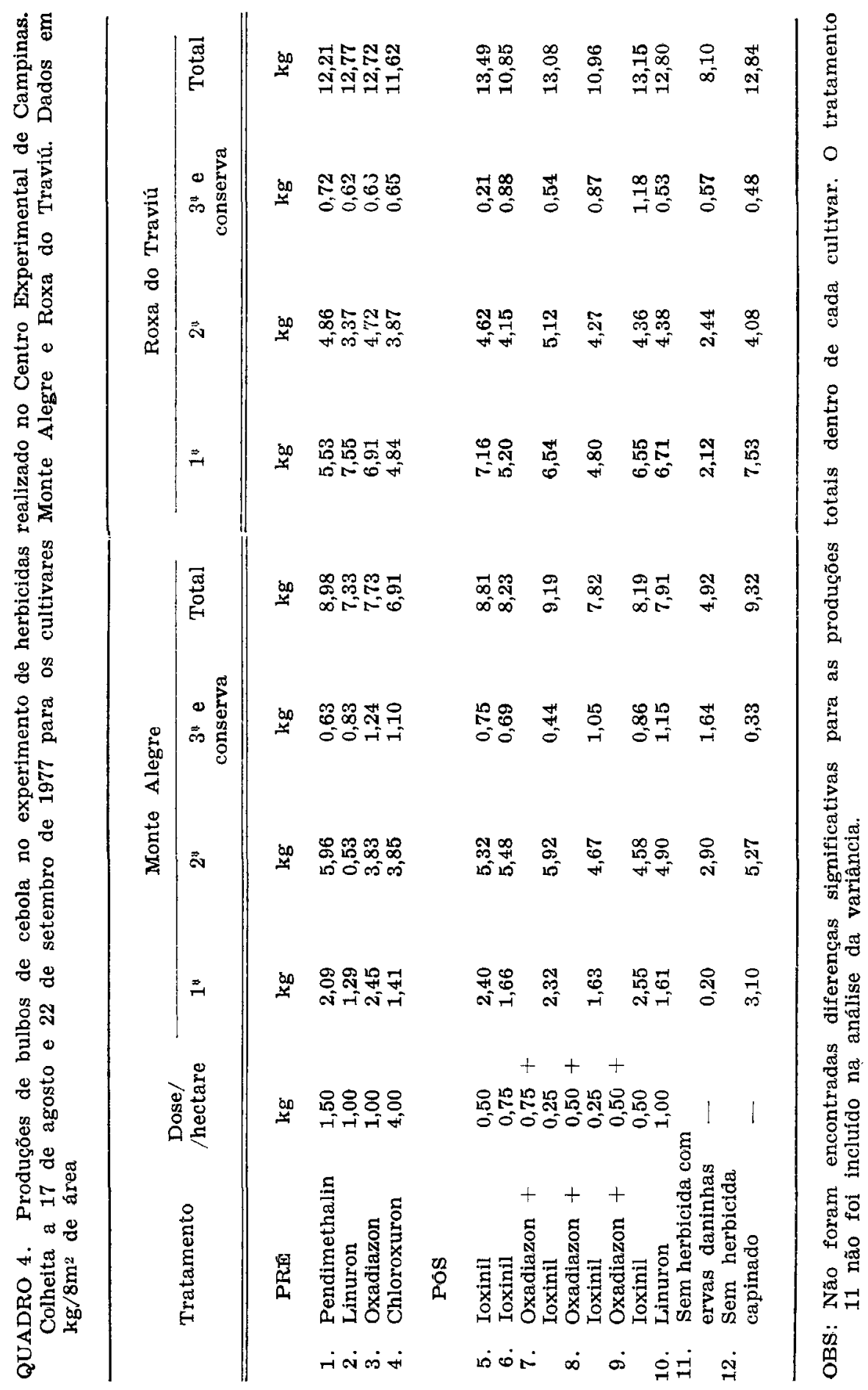


A produção de bulbos de cebola não apresentou diferenças significativas entre tratamentos, o que se deve ao excelente controle geral realizado por todos os herbicidas. A testemunha com ervas daninhas, que foi capinada aos 72 dias, apresentou quedas de produção muito elevadas de bulbos de primeira e de segunda, nos dois cultivares, e de produção geral de $47 \%$ e de $37 \%$, respectivamente, para os cultivares Monte Alegre e Roxa do Traviú. Em tra- balho anteriormente conduzido, foi verificada queda de produção de $73 \%$ com tratamento de 66 dias iniciais com ervas daninhas (1). Esse resultado mostra que os efeitos da competição sobre a cebola variam com as espécies de ervas daninhas e densidade de ocorrência, além de fatores do solo e de clima.

O cultivar Roxa do Traviú apresentou produçōes significativamente mais elevadas que $o$ Monte Alegre.

\section{SUMMARY}

\section{EFFECT OF DIFFERENT HERBICIDES ON GARLIC AND ONION CROPS}

Two field trials with garlic 'Lavinia' and onion 'Monte Alegre' and 'Roxa do Traviú' were performed on a loamy soil to study herbicide selectivity and their efficiency on weed control.

The following treatments were studied on garlic: pendimethalin at 1.50 $\mathrm{kg} / \mathrm{ha}$; linuron at $1.00 \mathrm{~kg} / \mathrm{ha}$ and oxadiazon at $1.00 \mathrm{~kg} / \mathrm{ha}$, applied in pre-emergence at the planting day; ioxynil at 0.50 and $0.75 \mathrm{~kg} / \mathrm{ha}$, ioxynil + oxadiazon at $0.75+0.25 \mathrm{~kg} / \mathrm{ha}$ and $0.50+0.50 \mathrm{~kg} / \mathrm{ha}$, applied 35 days after, weeded and hoed checks and a check with mulch.

The weed population was a mixture of various types of weeds; predominated by Portucala oleracea L. Weed control was evaluated at 48 and 84 days. All treatments controlled very well the dicotyledons. Ioxynil alone or mixed with oxadiazon in post-emergence did not control grasses. None of the herbicide treatments reduced the garlic stand, occurring the lowest number on the checks with weeds and mulch. The yields occurred in the following:

hoed check $>$ oxadiazon $>$ ioxynil + oxadiazon at $0.50+0.50 \mathrm{~kg} / \mathrm{ha}=$ pendimethalin $=$ mulch $=$ icxynil + oxadiazon at $0.75+0.25 \mathrm{~kg} / \mathrm{ha}>$ linuron $>$ ioxynil at $0.75 \mathrm{~kg} / \mathrm{ha}>$ ioxynil at $0.50 \mathrm{~kg} / \mathrm{ha}>$ weeded check.

On the onion crop the following treatments were studied: pendimethalin at $1.50 \mathrm{~kg} / \mathrm{ha}$, linuron at $1.00 \mathrm{~kg} / \mathrm{ha}$, oxadiazon at $1.00 \mathrm{~kg} / \mathrm{ha}$, and chloroxuron at $4.00 \mathrm{~kg} / \mathrm{ha}$, applied in pre-emergence on the day of transplänting; ioxynil at 0.50 and $0.75 \mathrm{~kg} / \mathrm{ha}$, oxadiazon + ioxynil at $0.75+0.25 \mathrm{~kg} / \mathrm{ha}$, at $1.00+0.25$ $\mathrm{kg} / \mathrm{ha}$ and at $1.00+1.00 \mathrm{~kg} / \mathrm{ha}$ and linuron at $1.00 \mathrm{~kg} / \mathrm{ha}$, all applied 32 days after, weeded and hoed checks.

The weeds occurring were predominantly dicotyledons being Portulaca oleracea L. and Chenopodium album L. the most dominant. Control evaluation was done at 48 days showing an excelent control of dicotyledons (over 95\%) by all treatments. Ioxynil alone or mixed with oxadiazon did not control grasses and chloroxuron showed the lowest general control but yielded satisfactory. Oxadiazon in pre-emergence and linuron in post-emergence were the most efficient in controling gresses. There were no differences among treatments for bulb yield. 


\section{REAERENCIAS BIBLIOGRAFICAS}

1. DEUBER, R. \& FORSTER, R. Efeitos da competição do mato na cultura da cebola (Allium cepa L.). Campinas, Instituto Agronômico, 1975. 21p. (Boletim Técnico, 22)

2. - - - CAMPOS, H. R.; MARTINS, F. P.; SCARANARI, H. J. Experimentos com herbicidas em culturas de cebola. Campinas, Instituto Agronômico, 1977. 20p. (Boletim Técnico, 47)

3. FERREIRA, F. A. \& SILVA, J. F. da. Herbicidas na cultura do alho. Informe Agropecuário, Belo Horizonte, 4(48):35-38, 1978.

4. — SILVA, J. F. da Plantas daninhas e seu controle na cultura da cebola. Informe Agropecuário, Belo Horizonte, 6(62):35-40, 1980.

5. - ; SILVA, R. F. da. Controle químico de ervas daninhas na cultura da cebola (Allium cepa L.). Revista Ceres, Viçosa, 25:486-490, 1978.

6. KLINGMAN, C. G. \& ASHTON, F. M. Weed Science: principles and practices. New York, J. Wiley, 1975. 431p.

7. MELfI, A. J.; GIRARDI, A. V.; MONIZ, A. C. Mineralogia dos solos da Estação Experimental "Theodureto de Camargo", em Campinas. Bragantia, Campinas, 25:9-30, 1966.

8. RHôNE-POULENC. Bromoxynil and ioxynil, selective weed killers. Lyon. Rhône-Poulenc-Phytosanitaire, 1977. 31p. 